\title{
Using WorldShare Collection Evaluation to Analyze Physical Science and Engineering Monograph Holdings by Discipline
}

\begin{abstract}
Academic libraries are challenged with managing collection budgets for purchasing multidisciplinary ebook packages, while equitably distributing funds for print and electronic monographs across subjects. McGill Library's science and engineering monograph holdings were analyzed using OCLC's WorldShare Collection Evaluation (WCE). Researchers mapped Conspectus subject divisions and categories to relevant university departments and evaluated holdings in comparison with department metrics to provide a fuller picture for collection development decision making. Findings show that WCE can be used in combination with circulation data and enrollment and staffing numbers to provide insight into the purchasing and use patterns of monographs down to the department level.
\end{abstract}

\section{KEYWORDS}

WorldShare Collection Evaluation; Collections management; Collection analysis; Assessment tool; Academic libraries

\section{INTRODUCTION}

The McGill University Library System is a network of 13 individual libraries and special collections, spread across two campuses: the downtown campus with 12 libraries, and the Macdonald campus with one library. With the exception of the Faculty of Agricultural and Environmental Sciences and the School of Dietetics and Human Nutrition, the Schulich Library of Science and Engineering (located downtown) serves all faculties and schools in 


\section{Using WCE to analyze monograph holdings by discipline}

medicine, life and physical sciences, and engineering. There are 13 departments and schools that fall under physical sciences and engineering. As of 2014-15, these departments represented a total of 7,036 users: 423 faculty (as determined by consulting each department's website) and 6,613 students consisting of 187 postdoctoral, 1,024 Ph.D., 704 masters, and 4,698 undergraduate students (McGill Enrolment Services 2015).

Acquisition of print and electronic library materials is coordinated centrally through the Collection Services department. Monograph selection is carried out both centrally by the collection department and by the many liaison librarians, each responsible for one or more departments. The overall collection budget for the library system in 2014-15 was \$16M (Canadian dollars) with a breakdown of 70\% for serials and 30\% for monographs. The monograph budget is allocated throughout the individual libraries with a general breakdown of $50 \%$ for firm orders and $50 \%$ for approval plans. In 2005 , the library initiated print approval plans with Yankee Book Peddler (YBP); this was followed by similar setups with Coutts, Amalivre, Casalini Libri, and Harrassowitz. This initiative was to move as much as possible away from the pick and choose model to allow liaison librarians more time to perform outreach, teaching, and other professional and scholarly activities. In 2012-13, YBP print approval plans (YBP representing the major book supplier) were turned into e-preferred ones. Whenever a book is available in both print and online formats, the electronic version is purchased.

Two catalogues are currently available to users to retrieve the information they need: Aleph from Ex Libris and WorldCat Local. With the quantity of ebooks that the library is acquiring - around 200,000 per year - it became very difficult for staff to individually 


\section{Using WCE to analyze monograph holdings by discipline}

catalogue them all for access via Aleph. Because of this, the library decided to rely more heavily on the WorldShare knowledge base for the discovery of e-resources. In May 2014, all electronic titles were removed from the Aleph catalogue and made available only via WorldCat Local. The classic catalogue (Aleph) is now used mainly for circulation purposes since it only contains print materials. Over 2 million ebook titles are now available at McGill, which represents approximately $50 \%$ of all monographs. Ebook packages that are purchased centrally by the collection department every year consist of Cambridge UPO, Elsevier, Oxford UPSO, Palgrave, Project MUSE UPCC, Springer, and Wiley.

The Schulich Library monograph budget for physical sciences and engineering subjects in 2014-15 was $\$ 214,000$. However, this does not take into account ebook packages that are purchased centrally. It is very difficult to give the actual dollar amount that is spent on behalf of physical sciences and engineering. Collection development in these subject areas is handled by four liaison librarians, each assigned three or four departments.

Ebook packages that are more tailored to science and engineering, such as American Geophysical Union, Books24x7 (ITPro, EngineeringPro), IEEE, IGI Global, Knovel, Royal Society of Chemistry, Safari Tech Books Online, and World Scientific are either purchased or subscribed to as recommended by liaison librarians.

Up until the 2011-12 fiscal year, the monograph budget in Schulich Library was allocated between the 13 departments it served. With the purchase of more and more ebook packages along with the increasingly interdisciplinary nature of research, it became very difficult to manage so many funds. In 2012-13, monograph allocations for physical 


\section{Using WCE to analyze monograph holdings by discipline}

sciences and engineering were folded into a single fund. This change provided more flexibility and reduced possible conflicts in determining which fund should be charged for a given monograph. In the context of this newly shared budget among physical sciences and engineering, librarians were curious to discover what the distribution of monographs was across the various subjects. Bearing in mind the degree to which physical sciences and engineering departments are interdisciplinary, the goal was to ensure that the shared funds be spent in a way that meets the needs of each department.

Schulich Library holds a total of 155,000 print items in science and engineering, representing 133,368 titles. The branch's collection has the following Library of Congress classification distribution percentages for its print science and engineering collection:

- A - General works (7\%) representing mainly master and $\mathrm{PhD}$ theses

- G - Geography, Anthropology, Recreation (4\%)

- $\mathrm{H}$ - Social Sciences (2\%) mainly in transportation

- Q - Science $(48 \%)$

- $\mathrm{T}$ - Technology (36\%)

- $\operatorname{Other~(3\% )~}$

The purpose of this study is to use OCLC's WorldShare Collection Evaluation (WCE) (a subscription product, details of which are available at: www.oclc.org/collectionevaluation.en.html) to generate a bird's eye view of the current physical sciences and engineering monograph collection. The project was initially undertaken as a McGill School of Information Studies graduate student 100-hour practicum project in winter 2015. WCE was used to analyze the collection in terms of its breakdown by subject, age, format 


\section{Using WCE to analyze monograph holdings by discipline}

(electronic and print), and circulation patterns. Results were compared to demographic data of academic departments, with the goal of better aligning collection development with user needs. The study addresses the following questions:

- How do subject-level collections in physical sciences and engineering relate to one another in terms of monograph holdings, age, format, and circulation patterns?

- How do collection statistics compare to enrolment and staffing of physical sciences and engineering departments that are supported by Schulich Library?

- How can data acquired using WCE assist librarians with collection development decision making?

\section{LITERATURE REVIEW}

Although there are various tools and services that can be used to analyze and compare library collections (several of which are outlined by Machovec 2014), this literature review will focus on WCE since it was the primary tool used for analyzing the collection in the current study. WCE has undergone several name changes over time, having been called WorldCat Collection Analysis as late as summer 2014 and subsequently renamed to WorldShare Collection Evaluation. Occasionally, the tool is also referred to as OCLC Collection Evaluation (Machovec 2014; Kelly 2014). There is some literature on using WorldCat data without the Collection Evaluation component (McClure 2009; Kohn 2013) and some that mention methods or products other than WCE or WorldCat for collection evaluation purposes (White 1995; Kelly 2014; Ferguson 2015). These are discussed when their findings are considered to be relevant. 


\section{Using WCE to analyze monograph holdings by discipline}

Libraries have used WCE for various purposes, including benchmarking against peer institutions, collection building, collection sharing, deselection, and accreditation. There are many articles that focus on benchmarking one specific discipline against peer institutions, such as Hubbard and Neville (2012) for mechanical engineering; Genoni (2013) for design; Benedetto Beals and Gilmour (2007) for zoology; McClure (2009) for romance languages; and Pettijohn, Etzel, and Killenberg (2013) for graphic design. There are others that report using WCE for benchmarking a limited number of specific subjects, such as linguistics, arts management, and forensic science (Kelly 2014); and art and architecture, sociology, and medicine (Genoni and Wright 2010), as well as some that use WCE to benchmark entire collections or a wide array of subject areas (Monroe-Gulick and Currie 2011; Henry, Longstaff, and Van Kampen 2008; Culbertson and Wilde 2009; Spires 2006). Benchmarking features in WCE can assist users in evaluating the quality of collections. Monroe-Gulick and Currie (2011) note that benchmarking allows researchers to determine the strength of their university libraries' collection based on the overlap between their collection and the collections of their "aspirational peers". Genoni and Wright (2010) use benchmarking to determine the uniqueness of a collection, which helps inform decisions about its management (198). Most papers report on benchmarking of actual collections. However, McClure (2009) employs WorldCat data to form a fictional aspirational collection with which to compare its holdings, rather than comparing with an actual existing peer library.

Besides benchmarking, WCE can be used for purposes such as establishing new collections. For example, Dzurak, Falloon, and Cope (2015) explain that WCE enabled researchers to identify areas of the collection that were adequate, and other areas that needed attention when the library took on support of the new program of East Asian 


\section{Using WCE to analyze monograph holdings by discipline}

studies. By comparing with libraries that one may aspire to, librarians can use WCE to generate title lists for making acquisitions. Some articles report combining WCE with other forms of analysis for collection development purposes, such as evaluation of interlibrary loan statistics (Davis, Day, and Orcutt 2008; Henry, Longstaff, and Van Kampen 2008; Kelly 2014), the brief test method - first developed by White (1995) - where a subject specialist compiles a short list of important titles to check against a library's holdings (Benedetto Beals and Gilmour 2007; Kelly 2014), and citation analysis (Kelly 2014; Dzurak, Falloon, and Cope 2015).

WCE facilitates collection sharing by multiple institutions, as well as deselection projects. Genoni's 2013 study compares holdings at several institutions with the goal of determining WCE's effectiveness as a means of developing a collaborative storage system for collections. As he and Wright report in an earlier paper (2010), WCE can be used for the following purposes: decision making related to new acquisitions and retention of unique titles, interlibrary loan, deselection, and storage of items in a collaborative fashion. Ferguson's analysis points to WCE as one of several tools that could be used for deselection and mentions the advantages of pairing a collection analysis tool with a "rules-based approach" to increase efficiency and objectivity in the deselection process $(2015,18)$. Ward and Aagard (2008) use WCE for a serials deselection project and explain that it allowed staff to quickly compare where the library's holdings may have been duplicated elsewhere, a task that would have been "prohibitively time consuming" without the tool (282).

Previous literature highlights WCE's many advantages. Genoni and Wright (2010) describe one of its biggest strengths as being that the "software has the potential to enable 


\section{Using WCE to analyze monograph holdings by discipline}

far more detailed comparison of ... collections than has previously been possible" (197), allowing library staff to do detailed comparisons of their collections to others by using an important international union catalogue. The data inherent in WorldCat can be accessed and analyzed rapidly and provides a high level of detail. By using this data, a library can benchmark their own collection - or the collection of a group of libraries - against international collections. Currently, there is little on the market that can compete with the type of information that is possible to acquire through WCE. The tool allows users to be able to compare the quality of their collections in a way that requires significantly less time, resources, and expertise than other tools. For example, using WCE for collection analysis allowed Genoni (2013) to quickly and easily determine that in the field of design, a specific library used in his comparison was making an important contribution to holdings held nationally. McClure (2009) points out the ease with which WCE can identify collection gaps down to the individual title level. Benedetto Beals and Gilmour (2007) demonstrate another advantage: the tool requires considerably less subject knowledge for the assessing librarian than other collection evaluation methods. According to Ciszek and Young (2010), WCE is an especially valuable tool for analyzing large collections as it is able to provide a big picture of the collection when physical shelf reading is not feasible. Henry, Longstaff, and Van Kampen (2008) used WCE to demonstrate the value of purchasing specific types of formats such as ebooks. The authors were able to substantiate that the purchase of ebooks improved the average age of items in the collection. These advantages make WCE a central and versatile tool for collection analysis.

Several authors also point out WCE's limitations, one of which is how difficult it is to conduct analysis of interdisciplinary topics. Burke (2010) reports that interdisciplinary 


\section{Using WCE to analyze monograph holdings by discipline}

topics are "almost impossible to assess ... with this tool" (20). Ciszek and Young (2010) mention that WCE has limitations when used to examine interdisciplinary subjects that span many call number ranges. Dzurak, Falloon, and Cope (2015) concur, stating that there is no ideal tool for analyzing small interdisciplinary subject areas. Benedetto Beals and Gilmour (2007) discuss weaknesses of WorldCat records that render peer evaluation problematic, such as problems with "multiple records, copious editions, duplicate title listings, and inconsistent reporting or cataloging" (107). Hubbard and Neville (2012) claim that WCE over-reports on uniqueness of titles held and that the Conspectus can be rigid. In addition, benchmarking can be problematic if peer institutions use more than one OCLC symbol since, when conducting comparisons, only one OCLC symbol can be used for each institution (Hubbard and Neville 2012). Orcutt and Powell (2006) note the extent to which these limitations impede use of the tool, stating that "the accuracy of the data and its ability to handle increasingly complex cataloguing records and collection decisions in a sophisticated, user-friendly way are necessary if OCLC truly wishes the tool to provide the type of information which could result in more informed decision-making" (46). University of Kansas librarians agree that there can be problems with WCE data with $44 \%$ of them identifying issues such as multiple records, uncatalogued items, and inconsistencies in cataloguing (Monroe-Gulick and Currie 2011). They also report many frustrations due to technical difficulties involving the tool timing out, which resulted in staff being unable to download reports. Many of the problems expressed in the literature relate to the quality of the records and have serious implications when using the tool for benchmarking purposes.

RESEARCH CONTRIBUTION 


\section{Using WCE to analyze monograph holdings by discipline}

The current study builds on the previous literature in several ways. It focuses on using the tool for internal analysis of a single library's collection, rather than for benchmarking and there are few that use WCE in this way. Hubbard and Neville (2012) is similar in that they use WCE to examine an engineering collection both internally to identify patterns in e vs. print book purchases over time, and externally to benchmark engineering collections in general and mechanical engineering collections in particular with peer institutions.

However, other studies focus on the benchmarking capabilities of the tool rather than its ability to identify useful collection patterns exclusively within one institution. With its focus on analyzing collections in the context of user needs, the current study's design is unique. By comparing data gathered through WCE with demographic data from the university's physical sciences and engineering departments, this study aims to use the tool in a way that has not yet been explored: to tell us something about our collections in relation to our own needs and to use the tool to help equitably balance the needs of all users of collections within physical sciences and engineering. This study also provides a unique contribution to the literature by mapping physical sciences and engineering departments to the OCLC Conspectus so that the subject areas reflect liaison collection areas. Representing collections in this way allowed for the addition of metrics on department size and the comparison of holdings and circulation statistics at the academic department level. Few studies to date incorporate analysis of circulation statistics into WCE. The researchers in this study use circulation data for the past 15 years to understand not only purchasing, but also use patterns. Finally, there are few papers that examine use of WCE for physical sciences and engineering disciplines specifically and none that tackle this subject area as a whole. 


\section{Using WCE to analyze monograph holdings by discipline}

This study's design avoids some of WCE's limitations, namely difficulties with cataloguing records displaying incorrectly when using data compiled across numerous libraries, problems with mapping subject areas (particularly interdisciplinary ones) to the OCLC Conspectus, and lack of cataloguing records for non-book items.

First, McGill Library uses WorldCat Local as its primary catalogue, and there have been great efforts to ensure that the library's holdings are well represented in WorldCat. Since McGill Library uses only one OCLC symbol, it simplifies the process of obtaining accurate data from WCE. As a result, using WCE exclusively for analyzing McGill Library physical sciences and engineering collections in relation to one another with regard to holdings, circulation, and format type mitigates some of the problems with employing WCE for benchmarking with other institutions whose holdings may not be as well-represented in OCLC.

Second, previous literature reveals that WCE works well for analysis of engineering subjects since they map easily to the OCLC Conspectus (Hubbard and Neville 2012), in contrast to interdisciplinary subjects which, as mentioned earlier, are difficult to analyze using WCE. Focusing on physical sciences and engineering reduces difficulties identified in the literature with mapping subject areas to the Conspectus for at least one of the two large subject areas analyzed in this study.

Third, this study's design uses WCE for analysis of monograph collections only. Researchers claim that it is better to use WCE for analyzing books rather than other format types since many libraries tend to underreport non-book items in WCE (Benedetto Beals and Gilmour 2007; Orcutt and Powell 2006) and since there are high rates of multiple 


\section{Using WCE to analyze monograph holdings by discipline}

records for like items in non-book formats (Orcutt and Powell 2006). For these reasons, limiting to book records simplifies the collection analysis task and renders the findings more reliable.

\section{METHODS}

Analysis of McGill Library WorldCat Holdings

Collection Evaluation was used within the OCLC WorldShare interface to analyze local WorldCat holdings. In order to determine subject-level coverage by department, the OCLC Conspectus upper two hierarchy levels (referred to by OCLC as divisions and categories) were mapped to university departments and schools in physical sciences and engineering that are supported by Schulich Library. Physical sciences departments include Atmospheric \& Oceanic Sciences (ATOC), Chemistry (CHEM), Earth \& Planetary Sciences (EPSC), Geography (GEOG), Mathematics \& Statistics (MATH), and Physics (PHYS), as well as the School of Computer Science (COMP). In engineering, there are the departments of Chemical Engineering (CHEE), Civil Engineering \& Applied Mechanics (CIVE), Electrical \& Computer Engineering (ECSE), Mechanical Engineering (MECH), and Mining \& Materials Engineering (MIME). The Department of Bioengineering was not included in this study as it has just recently been created. In addition, general science and general engineering groups were utilized for those call number ranges that could not be linked to a specific university department or school.

Three of the authors independently mapped the divisions and categories within the Conspectus to the respective physical sciences and engineering departments and schools. When required, a consensus was reached through discussion. Some of the categories did 


\section{Using WCE to analyze monograph holdings by discipline}

not map to any one department and were either included in the general science or engineering group or listed under "Excluded." An example of an excluded category is "Handicrafts, arts \& crafts," which does not correlate well with the studies of any of McGill's physical sciences or engineering departments. Table 1 illustrates how the categories in the OCLC Conspectus' "Engineering \& Technology" division were mapped to relevant engineering departments. The categories from five other divisions, Chemistry, Computer Science, Geography \& Earth Sciences, Mathematics, and Physical Sciences, were also considered. There was a total of 79 categories, across the six divisions, 10 of which were excluded. 


\section{Using WCE to analyze monograph holdings by discipline}

TABLE 1. Mapping of Conspectus "Engineering \& Technology" Division and its

Categories to Relevant Departments.

\begin{tabular}{|c|c|c|c|}
\hline $\begin{array}{c}\text { OCLC } \\
\text { Conspectus } \\
\text { Division }\end{array}$ & OCLC Conspectus Category & $\begin{array}{l}\text { LC Call } \\
\text { Number } \\
\text { Range(s) }\end{array}$ & $\begin{array}{l}\text { Mapped } \\
\text { Department }\end{array}$ \\
\hline \multirow{20}{*}{ 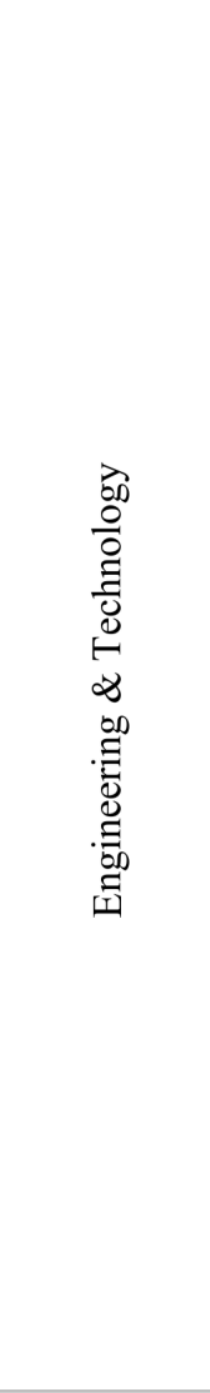 } & General Technology & $\begin{array}{c}\text { T0-57.61 } \\
\text { T57.65-58.5 } \\
\text { T58.64-9999 }\end{array}$ & $\begin{array}{c}\text { General } \\
\text { Engineering } \\
\text { (Gen. Eng.) }\end{array}$ \\
\hline & General Engineering & $\begin{array}{c}\text { TA0-220 } \\
\text { TA328-1629 } \\
\text { TA1651-9999 }\end{array}$ & CIVE \\
\hline & Hydraulic Engineering & ТС0-9999 & CIVE \\
\hline & Environmental Technology & TD0-9999 & CIVE \\
\hline & Highway Engineering & TE0-9999 & CIVE \\
\hline & Railroad Engineering & TF0-9999 & CIVE \\
\hline & Bridge Engineering & TG0-9999 & CIVE \\
\hline & Building Construction & TH0-9999 & CIVE \\
\hline & Mechanical Engineering \& Machinery & TJ0-9999 & $\mathrm{MECH}$ \\
\hline & Electrical Engineering & $\begin{array}{c}\text { TK0-5105.4 } \\
\text { TK5107-9999 }\end{array}$ & ECSE \\
\hline & Motor Vehicles, Aeronautics, Astronautics & TL0-9999 & $\mathrm{MECH}$ \\
\hline & Mining Engineering \& Metallurgy & TN0-9999 & MIME \\
\hline & Chemical Technology & ТР0-9999 & CHEE \\
\hline & Manufactures & TS0-9999 & CHEE \\
\hline & Handicrafts, Arts \& Crafts & ТT0-9999 & Exclude \\
\hline & Domestic Engineering & TX0-9999 & Exclude \\
\hline & Military Engineering & UG0-620 & Exclude \\
\hline & Navigation, Merchant Marine & VK0-9999 & Exclude \\
\hline & Naval Architecture, Shipbuilding, etc. & VM0-9999 & Exclude \\
\hline & Printing & Z116-277.9 & Exclude \\
\hline
\end{tabular}

The WCE formats 'Books: eBooks' and 'Books: Print, Non special format' were selected to represent the number of electronic and print monograph holdings by OCLC Conspectus subject category. The resulting monograph holdings data do not include special 


\section{Using WCE to analyze monograph holdings by discipline}

format items, such as braille. Summary tables were exported from WorldShare in March 2015, and spreadsheets were further analyzed using Excel.

In order to extract and analyze circulation metrics using WCE, a file of circulation data was created by running a circulation report for local physical items in Aleph (Ex Libris Group). It was sent to OCLC in November 2014 and included all items that circulated over an approximately 15-year period (beginning January 1, 2000 and ending November 18, 2014). The location of items and the dates that items circulated were not included in the report. To use WCE to analyze the collection by the number of times that print monographs circulated, researchers employed the 'circulated \# times in lifetime' function and filtered the display of WorldCat holdings using the format and publication date limits.

At the time of data collection, a portion of the mathematics and statistics collection was located in a library that was separate from Schulich Library. Approximately 5,240 monographs were included in the WorldCat catalogue from the Edward Rosenthall Mathematics \& Statistics Library, a small library serving the McGill Department of Mathematics \& Statistics. However, circulation data was not available for these titles and, therefore, WCE does not provide a complete picture of monograph circulation in these subject areas. Since this time, the Rosenthall Library has been closed and its contents merged with Schulich Library. Now that these monographs have been barcoded, circulation data is being gathered for all mathematics \& statistics monographs.

\section{University Department Information}

To gain perspective on the size of the departments in physical sciences and engineering, as well as the student populations that they serve, researchers consulted a variety of sources. 


\section{Using WCE to analyze monograph holdings by discipline}

The number of faculty professors was determined from each department's website, excluding sessional lecturers and emeritus professors. The number of students (undergraduate, graduate, and post-doctoral) enrolled in department major degree programs was determined using statistics from McGill Enrolment Services (2015). All data was entered into Excel spreadsheets for further analysis.

\section{RESULTS}

Monograph Holdings by Format

McGill Library holds a total of 4,114,468 monographs in WorldCat, with 49.4\% in electronic format. Of this total, there are 222,822 physical sciences monographs, $53.5 \%$ of which are electronic, and 155,999 engineering monographs, 53.9\% of which are electronic. When all other subject areas outside of science and engineering are combined, the percentage of electronic versus print monographs falls to $44.6 \%$. Monographs in WorldCat that are not assigned subjects using the OCLC Conspectus are given the category 'unknown'. Although a list of the 385,577 electronic monographs of unknown subject (not assigned call numbers) was extracted from WorldShare (19\% of total electronic holdings), given the large number of titles, it could not be determined under which major subject categories they could be placed.

The electronic versus print monograph holdings for each of the physical sciences' disciplines are presented in Figure 1. The highest percentage of ebooks (72.1\%) is found in computer science, followed by physics (52.2\%), mathematics \& statistics (51.3\%), chemistry (51.0\%), earth \& planetary sciences (40.5\%), general science (39.9\%), atmospheric \& oceanic sciences (39.1\%), and geography (38.2\%). Figure 2 shows the 


\section{Using WCE to analyze monograph holdings by discipline}

electronic versus print monograph holdings for each of the disciplines in engineering, along with a general engineering group. The highest percentage of ebooks (68.9\%) is found in electrical \& computer engineering, followed by general engineering (56.5\%), chemical engineering (53.7\%), mechanical engineering (53.5\%), civil engineering \& applied mechanics (52.3\%), and mining \& materials engineering (49.2\%).

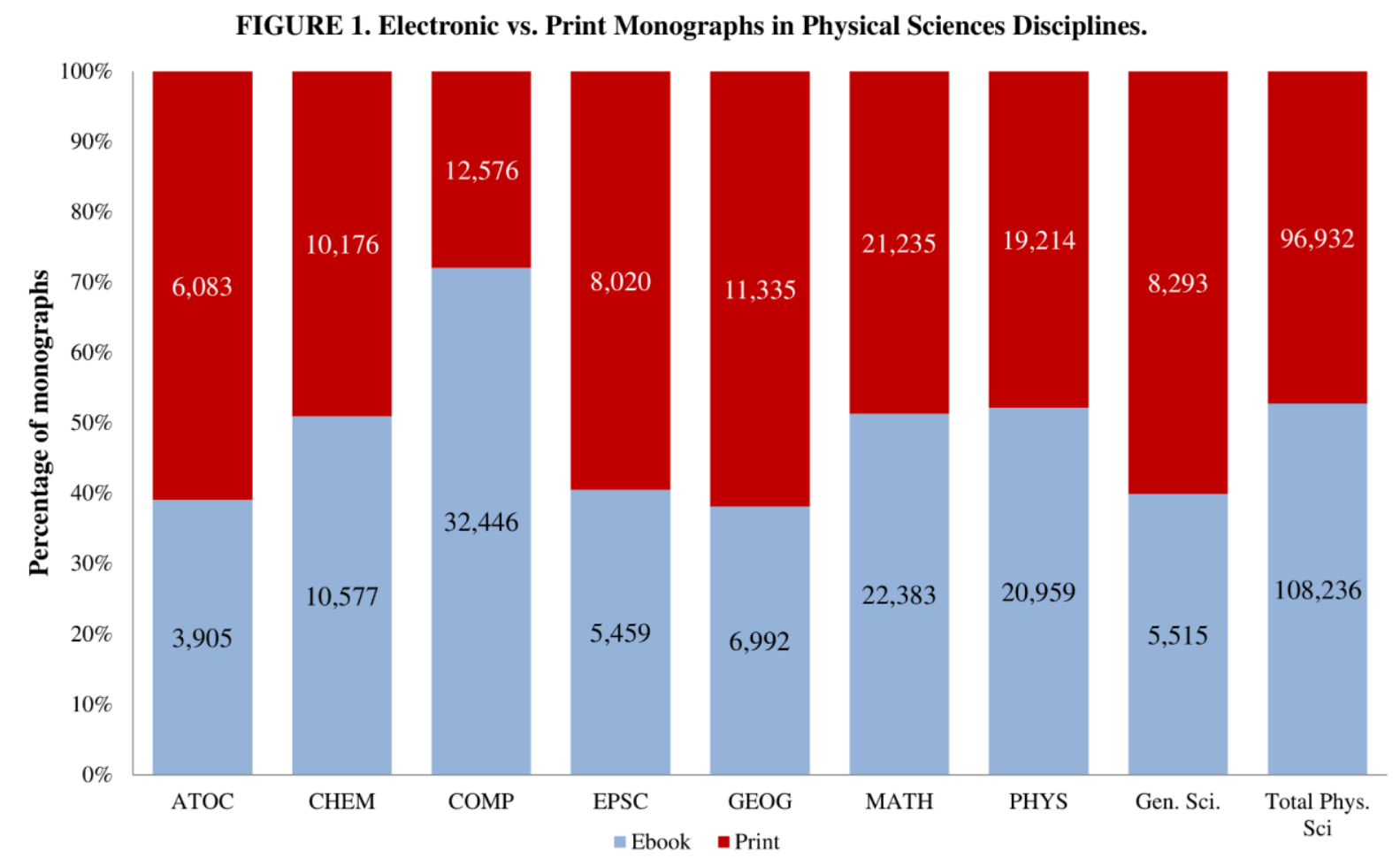

The number and percentages of monographs in electronic (bottom, blue) and print (top, red) format are provided for the physical sciences. The total of all of these physical sciences areas is also represented. 


\section{Using WCE to analyze monograph holdings by discipline}

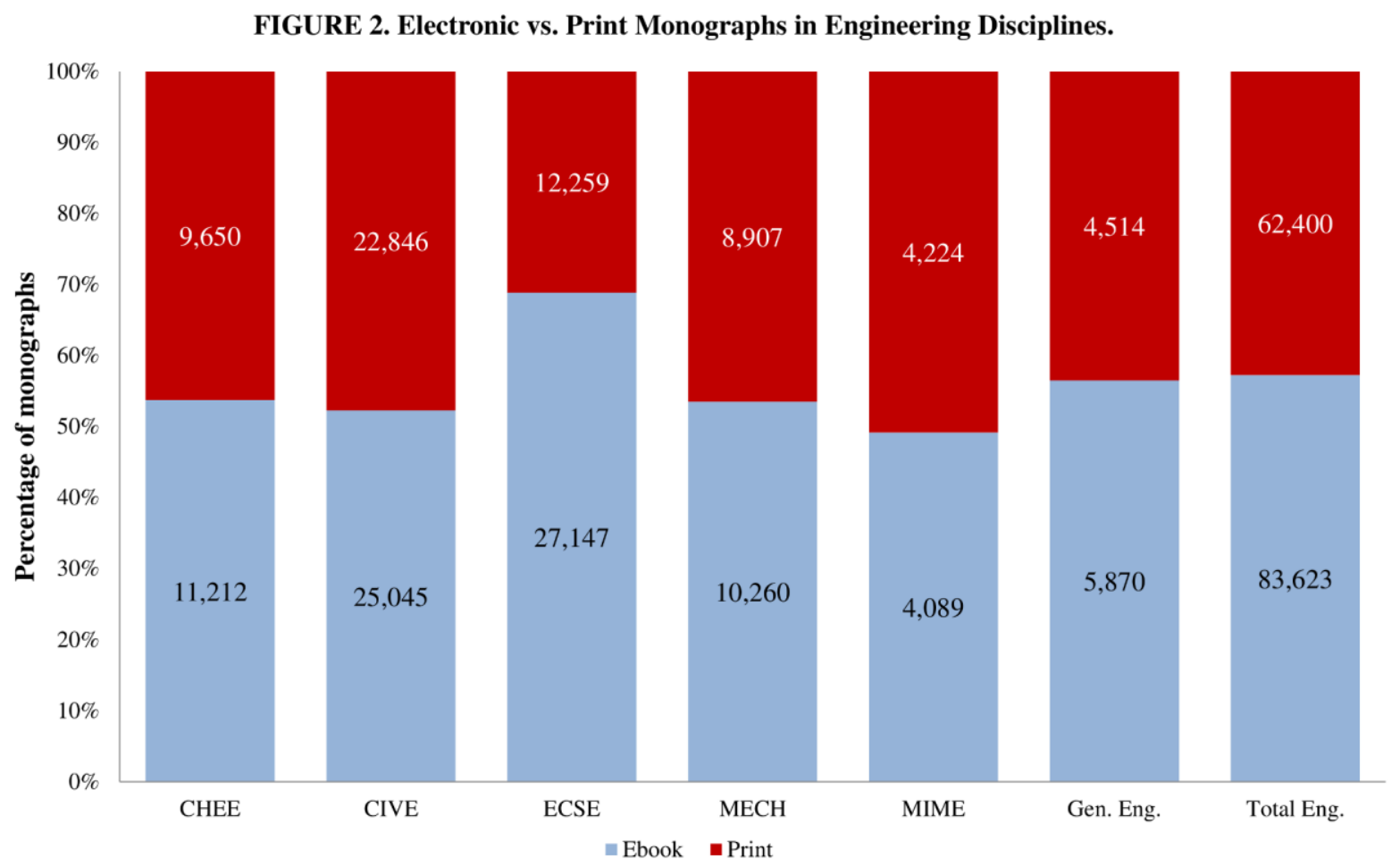

The number and percentages of monographs in electronic (bottom, blue) and print (top, red) format are provided for engineering. The total of all of these engineering areas is also represented.

Monograph Holdings by Format and Date of Publication

Over time, the purchasing trend has been toward electronic monographs in physical sciences and engineering (as demonstrated in Figures 3 and 4). For publication dates prior to 1990 , print and ebook holdings steadily rise, but for publication dates from the 1990s through the 2000s, the number of ebooks drastically increases.

Raw data of electronic and print holdings by department and publication date are provided in Tables 2 and 3, respectively. McGill has acquired more electronic than print monographs with a publication date of pre-1960 for all the engineering and science disciplines. The recent availability of large packages of archival electronic monographs, particularly in science and technology, accounts for the high percentage of pre-1960 


\section{Using WCE to analyze monograph holdings by discipline}

material in electronic format. These packages help to fill in gaps in the collection and allow low-use print material to be moved to storage in order to free up physical space in the library. The library also holds a higher percentage of electronic than print holdings for monographs published between 2010 and 2014. Conversely, for titles published between 1960 and 1990, the library holds more print than electronic monographs for all engineering and science disciplines, with the exception of electrical \& computer engineering and computer science.

FIGURE 3. Physical Sciences and Engineering Electronic vs. Print Monograph Holdings Published 1960-2009.

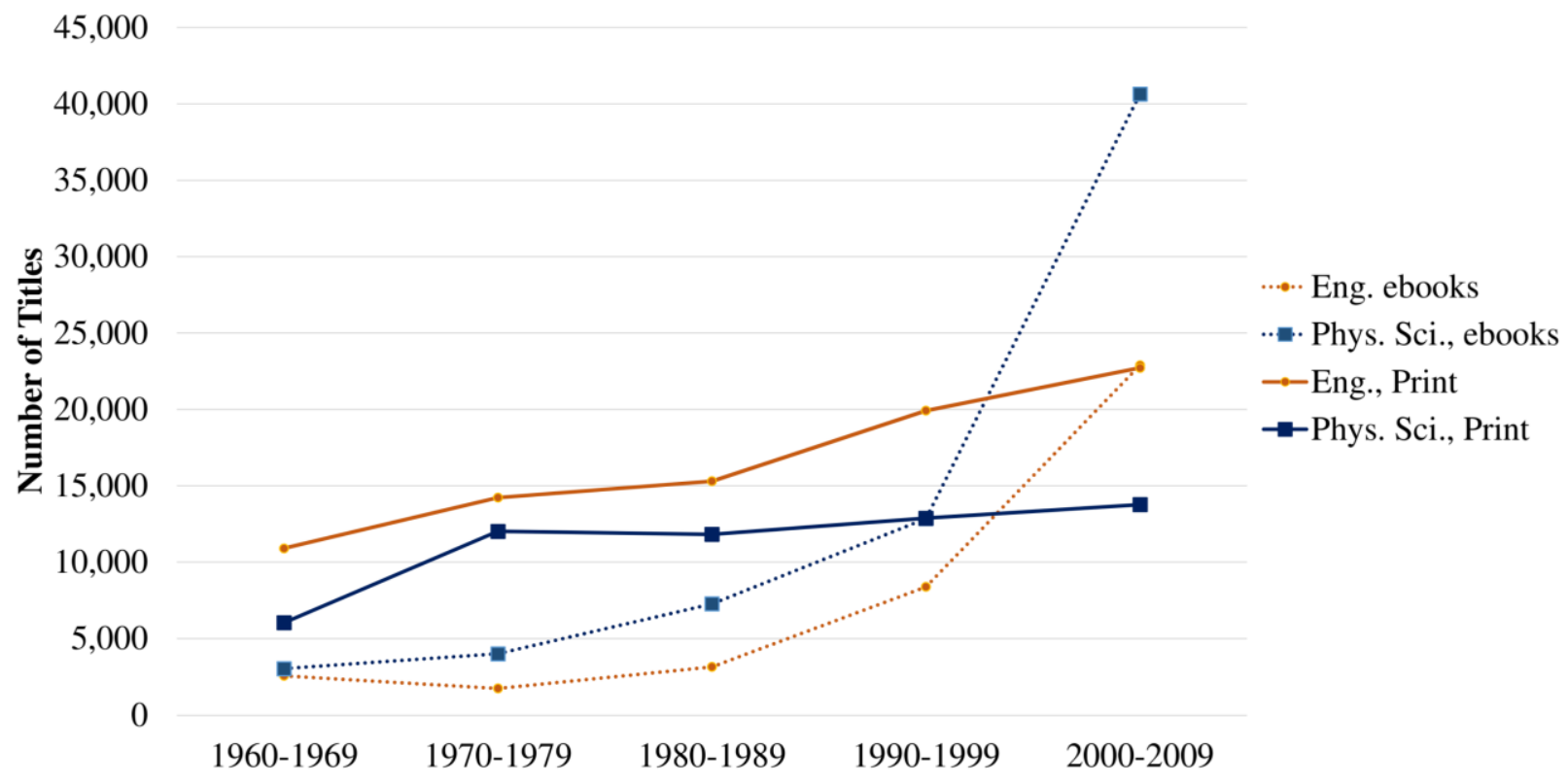




\section{Using WCE to analyze monograph holdings by discipline}

FIGURE 4. Physical Sciences and Engineering Electronic vs. Print Monograph Holdings Published 2010-2014.

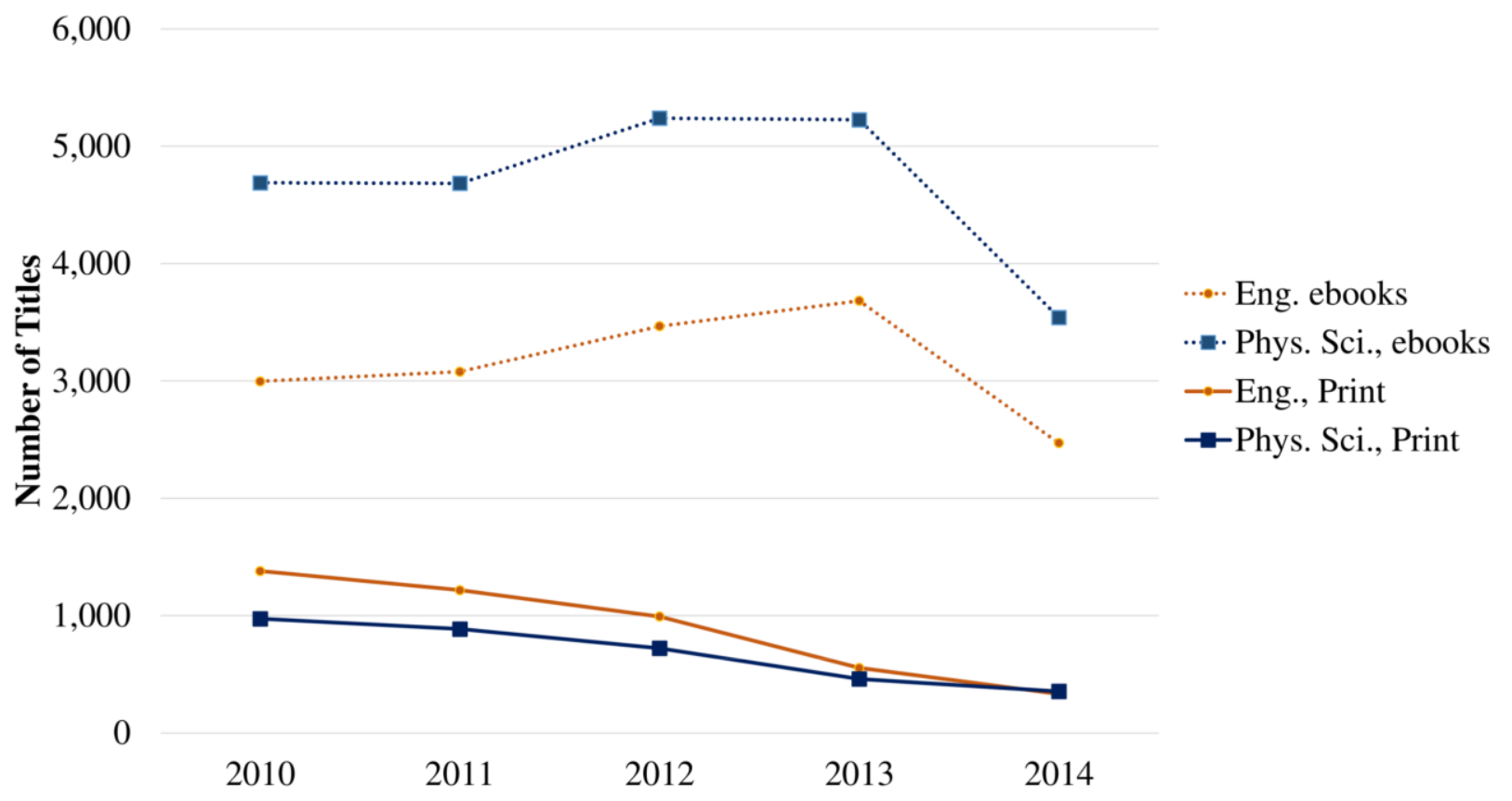




\section{Using WCE to analyze monograph holdings by discipline}

TABLE 2. Electronic Monographs for Physical Sciences and Engineering Disciplines by Publication Date.

\begin{tabular}{|c|c|c|c|c|c|}
\hline \multirow{2}{*}{ Faculty } & \multirow{2}{*}{ Department } & \multicolumn{3}{|c|}{ Publication date } & \multirow{2}{*}{ Total } \\
\hline & & Pre 1960 & 1960-2009 & $2010-2014$ & \\
\hline \multirow{6}{*}{ 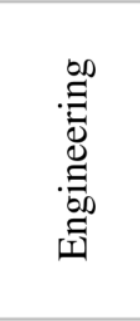 } & CHEE & 3,985 & 5,236 & 1,991 & 11,212 \\
\hline & CIVE & 8,430 & 11,979 & 4,636 & 25,045 \\
\hline & ECSE & 2,355 & 17,195 & 7,597 & 27,147 \\
\hline & $\mathrm{MECH}$ & 3,940 & 4,244 & 2,076 & 10,260 \\
\hline & MIME & 2,660 & 1,032 & 397 & 4,089 \\
\hline & Gen. Eng. & 1,765 & 2,824 & 1,281 & 5,870 \\
\hline \multirow{8}{*}{$\begin{array}{l}\ddot{U} \\
\stackrel{0}{0} \\
\ddot{n}\end{array}$} & ATOC & 1,028 & 2,192 & 685 & 3,905 \\
\hline & CHEM & 2,958 & 6,319 & 1,300 & 10,577 \\
\hline & COMP & 212 & 21,660 & 10,574 & 32,446 \\
\hline & EPSC & 3,302 & 1,799 & 358 & 5,459 \\
\hline & GEOG & 3,845 & 2,323 & 824 & 6,992 \\
\hline & MATH & 6,604 & 12,720 & 3,059 & 22,383 \\
\hline & PHYS & 6,939 & 11,471 & 2,549 & 20,959 \\
\hline & Gen. Sci. & 2,259 & 2,608 & 648 & 5,515 \\
\hline \multicolumn{2}{|c|}{ Excluded } & 7,430 & 2,908 & 1,101 & 11,439 \\
\hline \multicolumn{2}{|c|}{ Total* } & 49,181 & 103,602 & 39,076 & 191,859 \\
\hline
\end{tabular}

The total electronic monograph holdings are given for the publication dates of pre-1960, 1960-2009, and 2010-2014, along with the totals.

*Total includes Conspectus subcategories for physical sciences and engineering subject areas and an excluded category for monographs that were excluded from the listings by department because they did not fit into a Conspectus subcategory that was supported by Schulich Library. 


\section{Using WCE to analyze monograph holdings by discipline}

TABLE 3. Print Monographs for Physical Sciences and Engineering Disciplines by Publication Date.

\begin{tabular}{|c|c|c|c|c|c|}
\hline \multirow{2}{*}{ Faculty } & \multirow{2}{*}{ Department } & \multicolumn{3}{|c|}{ Publication date } & \multirow{2}{*}{ Total } \\
\hline & & Pre 1960 & $960-2009$ & $0-2014$ & \\
\hline \multirow{6}{*}{ 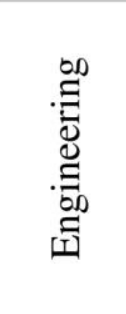 } & CHEE & 1,332 & 7,828 & 490 & 9,650 \\
\hline & CIVE & 2,105 & 19,719 & 1,022 & 22,846 \\
\hline & ECSE & 751 & 10,657 & 851 & 12,259 \\
\hline & $\mathrm{MECH}$ & 1,283 & 7,146 & 478 & 8,907 \\
\hline & MIME & 1,196 & 2,891 & 137 & 4,224 \\
\hline & Gen. Eng. & 577 & 3,720 & 217 & 4,514 \\
\hline \multirow{8}{*}{ 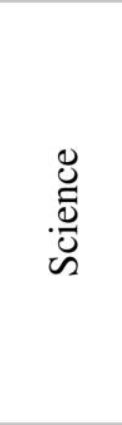 } & ATOC & 539 & 5,197 & 347 & 6,083 \\
\hline & CHEM & 1,617 & 8,334 & 225 & 10,176 \\
\hline & COMP & 33 & 11,985 & 558 & 12,576 \\
\hline & EPSC & 2,363 & 5,476 & 181 & 8,020 \\
\hline & GEOG & 2,608 & 8,107 & 620 & 11,335 \\
\hline & MATH & 3,029 & 17,507 & 699 & 21,235 \\
\hline & PHYS & 3,462 & 14,823 & 929 & 19,214 \\
\hline & Gen. Sci. & 1,771 & 6,215 & 307 & 8,293 \\
\hline \multicolumn{2}{|c|}{ Excluded } & 5,426 & 9,955 & 810 & 16,191 \\
\hline \multicolumn{2}{|c|}{ Total* } & 22,666 & 129,605 & 7,061 & 159,332 \\
\hline
\end{tabular}

The total print monograph holdings are given for the publication dates of pre1960, 1960-2009, and 2010-2014, along with the totals.

*Total includes Conspectus subcategories for physical sciences and engineering subject areas and an excluded category for monographs that were excluded from the listings by discipline because they did not fit into a Conspectus subcategory that was supported by Schulich Library.

Circulation of Print Monographs

The percentage of print books published between 2000 and 2014 that have never circulated at McGill Library is 44\%. In comparison, print monographs in physical sciences and engineering subject areas have a lower rate of non-circulation at 33\% and 28\%, respectively. The number of highly circulating books (21 or more times) is twice as high for physical sciences and engineering (at 8\%) as it is for McGill Library overall (at 4\%). In the sciences, mathematics \& statistics has the highest percentage of non-circulating books with 38\% (Figure 5). However, this figure does not take into consideration the collection of 


\section{Using WCE to analyze monograph holdings by discipline}

books at the former departmental mathematics \& statistics library that were included in the WorldCat catalogue but for which there was no circulation information. In WCE, these books count as never having circulated. When these titles are ignored, the percentage of non-circulating mathematics \& statistics books decreases to $25 \%$. The two remaining science disciplines with the highest percentage of non-circulating books (at 36\%) are geography and earth \& planetary sciences. The engineering subject area with the highest percentage of non-circulating books (at 41\%) is mining \& materials (Figure 6).

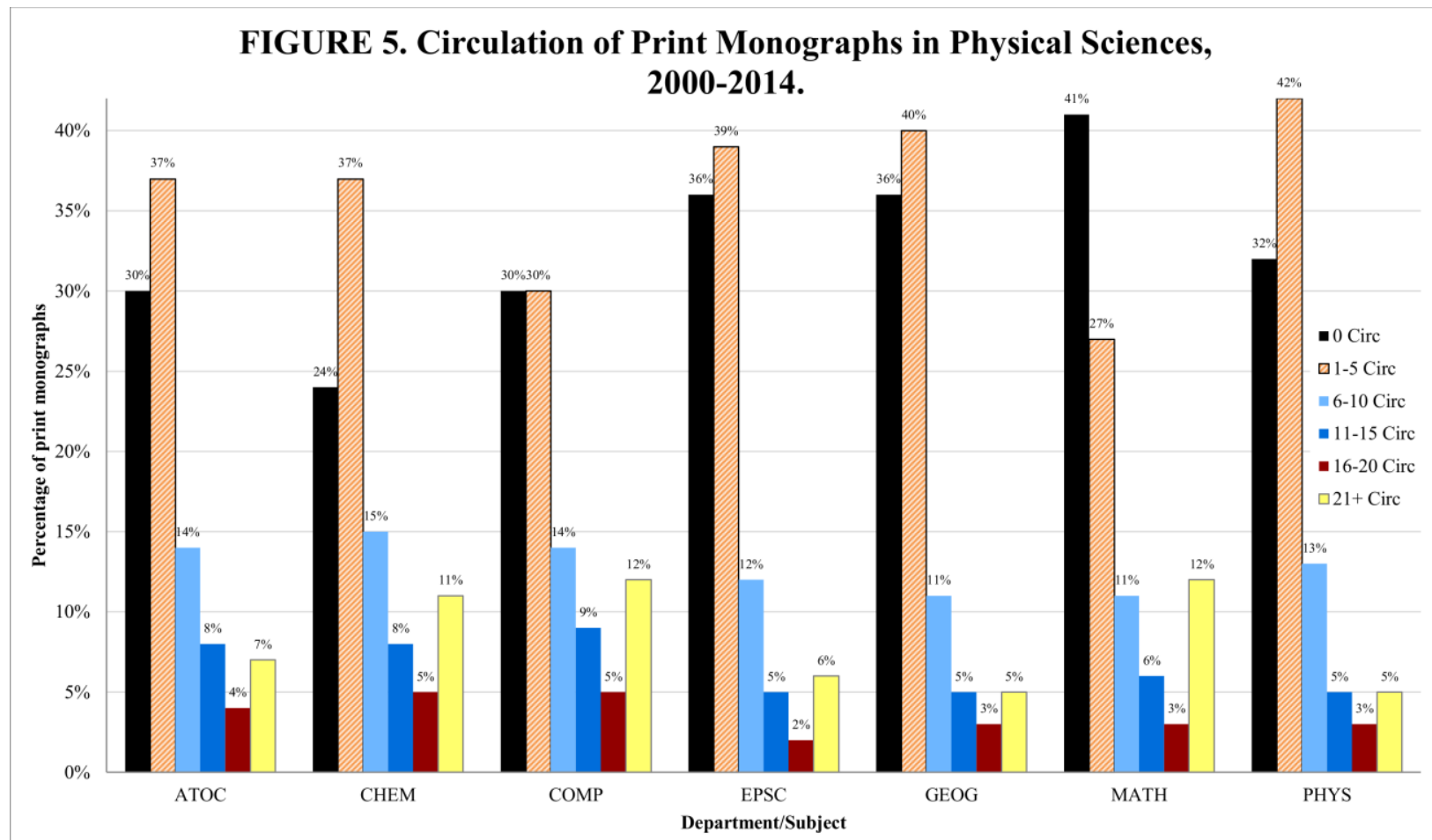

Data for print books (published from 2000 to 2014) that circulated between January 1, 2000 and November 18, 2014 are represented for sciences. Included are the percentage of books that never circulated ( 0 Circ), circulated 1 to 5 times, 6 to 10 times, 11 to 15 times, 16 to 20 times, or 21 or more times ( $21+$ Circ). Circulation information is not available for books held at the former Edward Rosenthall Mathematics \& Statistics Library, inflating the 0 Circ percentage for MATH. 


\section{Using WCE to analyze monograph holdings by discipline}

FIGURE 6. Circulation of Print Monographs in Engineering, 2000-2014.

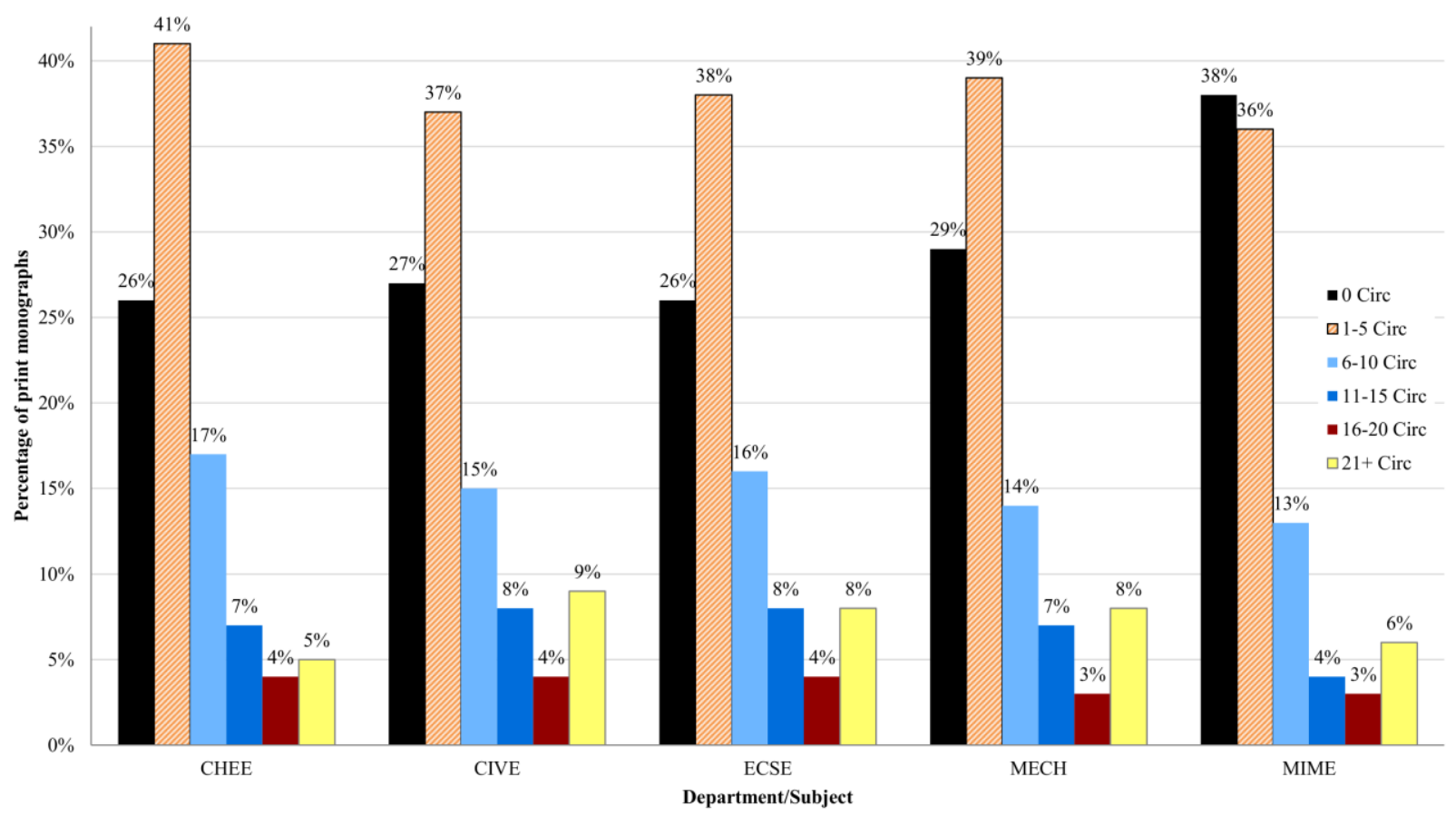

January 1, 2000 to November 18, 2014 circulation data for print books published between 2000 and 2014 are represented for engineering departments. Included are the percentage of books that never circulated ( 0 Circ), circulated 1 to 5 times, 6 to 10 times, 11 to 15 times, 16 to 20 times, or 21 or more times ( $21+$ Circ).

Department Metrics

Figure 7 provides an overall picture of the size of each department or school in physical sciences and engineering at McGill University. It includes the number of undergraduate and graduate students pursuing majors degrees, as well as postdoctoral students and academic faculty members. The largest of these is the Department of Electrical \& Computer Engineering. 


\section{Using WCE to analyze monograph holdings by discipline}

FIGURE 7. Department Size as Measured by Number of Students and Professors.

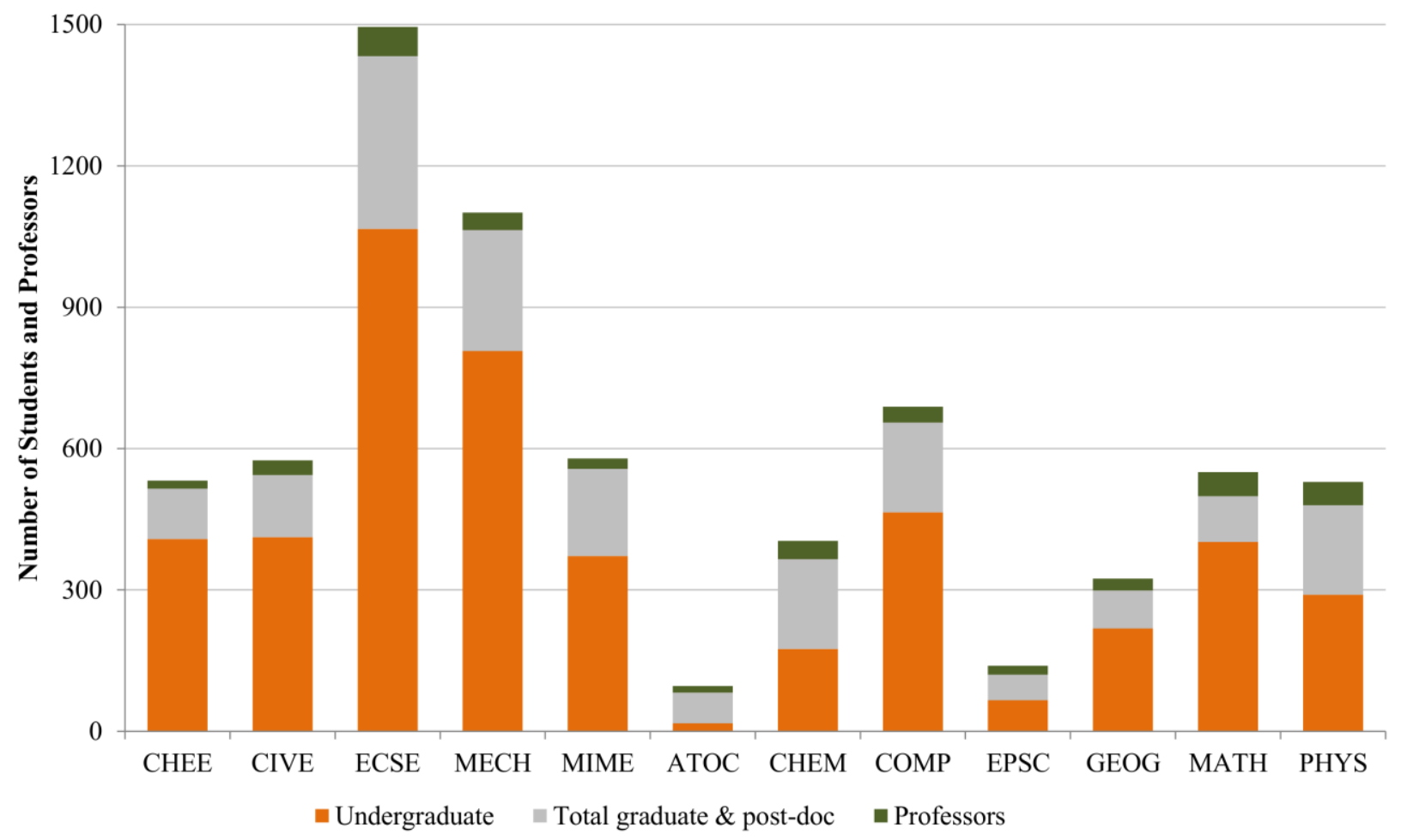

The number of students is by major and professors is by appointment in 2014 .

Figures 8 and 9 are a comparison of monograph collection and department size for physical sciences and engineering departments respectively. Civil engineering \& applied mechanics, mathematics \& statistics, atmospheric \& oceanic sciences, earth \& planetary sciences, and physics have large numbers of monograph holdings relative to the number of faculty and students in their respective departments, while electrical \& computer engineering, mechanical engineering, and mining \& materials engineering have larger numbers of faculty and students in their respective departments relative to their number of monograph holdings. 
Using WCE to analyze monograph holdings by discipline

FIGURE 8. Comparison of Monograph Collection and Department Size for Physical Sciences Departments.

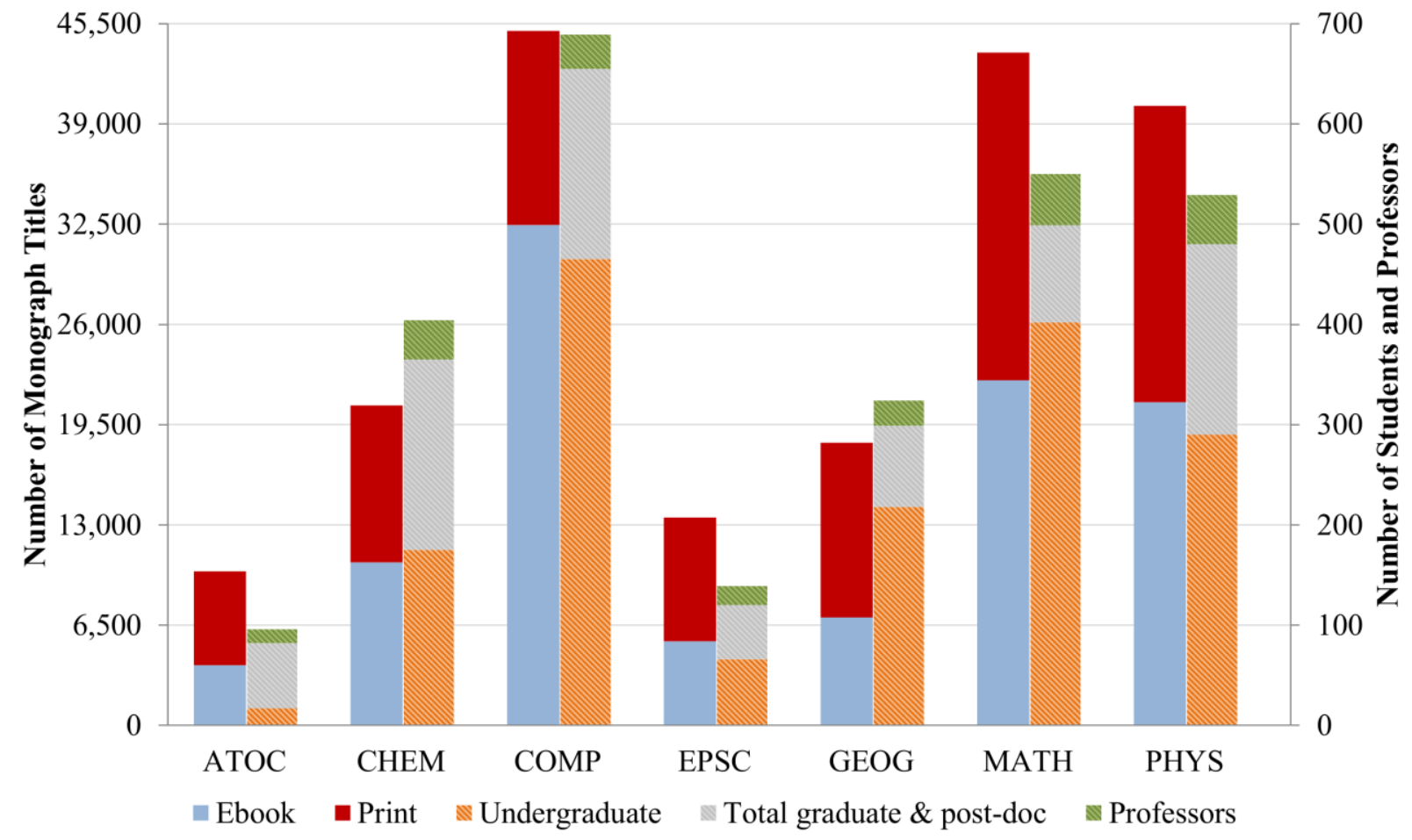

FIGURE 9. Comparison of Monograph Collection and Department Size for Engineering Departments.

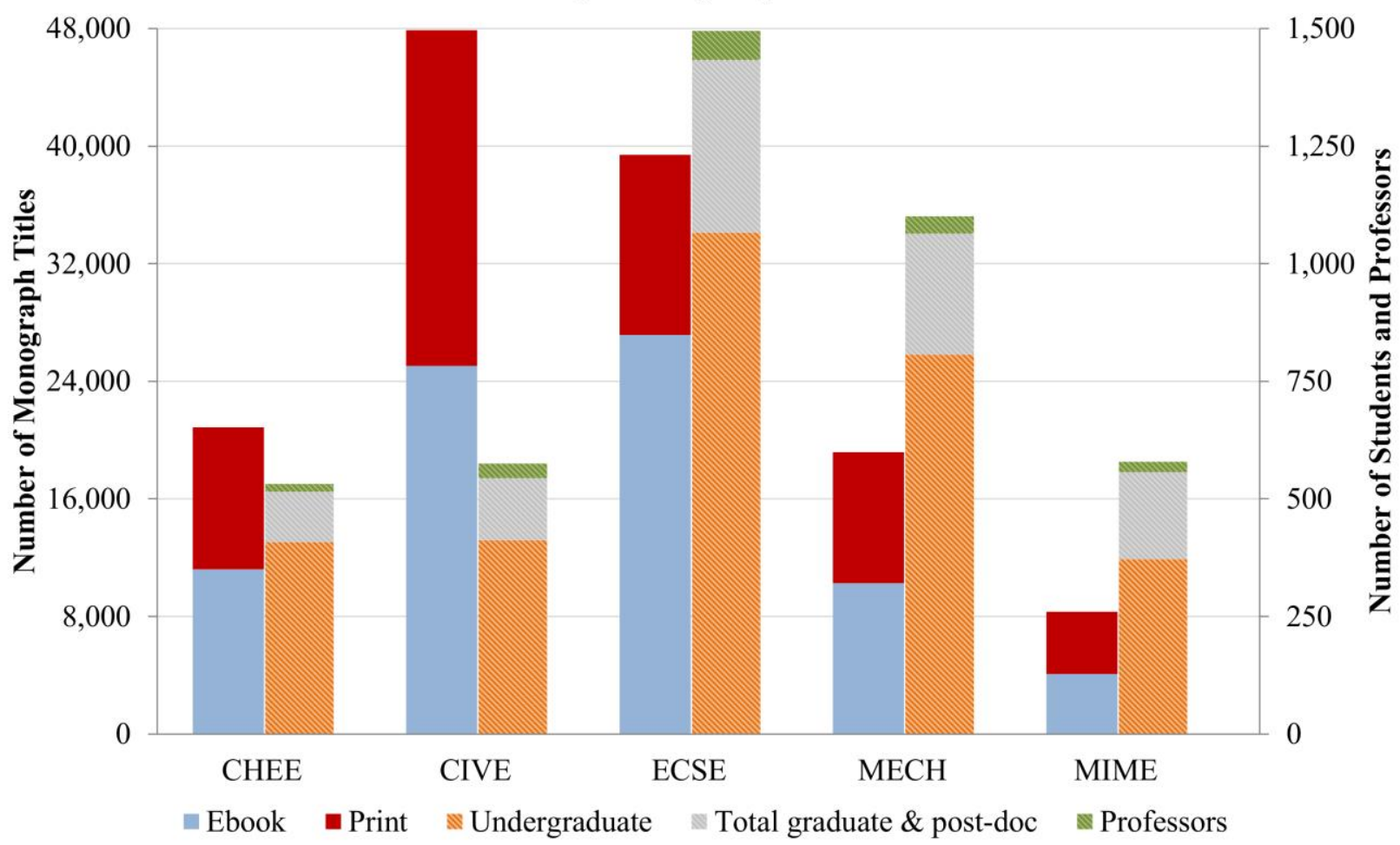




\section{Using WCE to analyze monograph holdings by discipline}

\section{DISCUSSION}

\section{McGill's Physical Sciences and Engineering Collection}

With monograph funds at McGill Library distributed into broad subject areas, liaison librarians in physical sciences and engineering designed this study to inform collaborative decision making. WCE was used for data collection and the subject divisions and categories outlined in the OCLC Conspectus were mapped to the supported university departments and schools. Without this step, it would have been difficult to gain a liaison perspective of the collection, in particular for the various fields of engineering and physical sciences. The data was then compared with metrics from the respective departments and the student populations that these departments serve.

When comparing the total number of monographs by discipline to the size of the corresponding departments, as shown in Figures 8 and 9, it is possible that certain disciplines may be under-resourced. Further investigation is needed into the publishing trends of particular subject areas, as well as the research and study needs of faculty and students in the departments with smaller holdings relative to the number of students and faculty. It would be useful to better understand the amount of interdisciplinary and multidisciplinary research performed, as well as students' and researchers' dependence on monographs versus periodical publications. Liaison librarians will need to examine approval plans already in place. If more intensive ebook or print book purchasing is necessary in given subject areas, it may require investment in packages from providers or publishers that were previously overlooked. 


\section{Using WCE to analyze monograph holdings by discipline}

Circulation in this study was measured by the number of times that print monographs published between 2000 and 2014 were loaned between January 1, 2000 and November 18, 2014. Overall, circulation is higher in physical sciences and engineering when comparing to McGill Library as a whole. However, this does not take into consideration that there are titles and collections across disciplines that do not go out on loan, such as rare books. Monographs in geography and earth \& planetary sciences have not circulated as much as other sciences, while circulation in mining \& materials engineering is notably lower than other areas of engineering. The current study only provides a partial picture of monograph usage, since McGill Library ebook COUNTER statistics were not loaded into WCE. It would be interesting and valuable to run a parallel comparison of circulation for ebooks, using the number of downloads and other usage statistics.

With recent efforts to include all ebook holdings in WorldCat, it was possible to get a picture of print versus electronic monographs for physical sciences and engineering disciplines, as well as for McGill Library overall. In the months since the data was collected, the number of electronic items in McGill Library has surpassed physical holdings, big news for a university that is over 190 years old - but this was already the case for physical sciences and engineering monographs. For publication dates after 2010, the number of print books purchased for the collection has slowly declined, while the library continues to invest in ebooks. Purchasing for 2014 was not complete at the time the data was generated, which may account for some of the decline in the number of 2014 monographs compared to the previous years. 


\section{Using WCE to analyze monograph holdings by discipline}

There is wide variation in the percentages of electronic versus print monographs in the science disciplines. Physics and mathematics have the highest number of books when considering only print titles but computer science catches up to their totals, thanks to a large ebook collection. With the exception of electrical \& computer engineering, which leads the way in terms of engineering monographs (perhaps due to the purchase of IEEE ebooks), there is less variation among engineering disciplines.

One of the limitations of using WCE to track ebook holdings by subject area is the large quantities that are placed in the unknown category. WCE assigns publications a division and category based on their call number. This call number can be NLM, LC, or Dewey, but it must be present. If documents are never assigned a call number - or were catalogued using a call number system that WCE does not recognize - then they are assigned to the unknown category. It is possible that many of these ebooks have received LC subject headings, but WCE does not capture this information. A brief and preliminary analysis of the unknown ebook title list did not reveal any one area where the books should be assigned. Rather, there was a large range of subjects and publishers represented by the titles. However, with approximately 400,000 items that do not have subjects, the number of ebooks assigned to a particular discipline may be a gross underestimation, particularly if one subject-specific ebook package did not include call numbers in their vendor-supplied cataloguing records. One way to gather more accurate collection analysis in the future would be to ensure that all ebooks are assigned call numbers in a format that is recognized by WCE. 


\section{Using WCE to analyze monograph holdings by discipline}

Lastly, the current study relied solely on department size to measure user needs in a given department. However, there are other factors to consider when determining what percentage of a library's collection budget should be spent in a given discipline. For example, one could examine the number of courses offered by a given department, both at the undergraduate and graduate level (especially courses provided to students enrolled in programs delivered by other departments). McGill's Departments of Chemistry and Mathematics \& Statistics offer many required undergraduate courses for students pursuing majors in other science and engineering departments. Part of the library's collections budget goes to purchasing copies of textbooks, including multiple copies when warranted by high enrolment numbers. That these two departments have higher monograph holdings than would be expected given their size, does not take into account the large number of students from other disciplines that rely heavily on chemistry and mathematics books for their studies.

Measuring user needs could also potentially include calculating research dollars per department, the number of monographs available to purchase in a given discipline per year, the average price of monographs per discipline, the extent to which students and researchers in a given department make use of materials from outside the call number ranges assigned to their respective departments, etc. An alternative method to conduct this study would have been to map subjects to more than one department. Some departments may be making greater use of materials from a wide variety of subject areas while others may be using materials more strictly within their own subject-designated call number ranges. For example, McGill's new Bioengineering Department was not discussed in this study because it was just created, but it is an example of a department that would likely be 


\section{Using WCE to analyze monograph holdings by discipline}

making use of materials in a wide variety of call number ranges in medicine, engineering, physics, and biology. A many-to-many mapping would perhaps provide a more accurate picture of how well such a department's needs are being met.

\section{CONCLUSION}

This study used an OCLC collection assessment tool, WCE, to analyze monograph holdings in order to inform decision making in the context of a shared monograph budget for physical sciences and engineering. It allowed for a clearer picture of the holdings relative to the size of each of the departments that the library supports. Using the tool provided librarians with an overview of the monograph collection by subject area, age, and format type, as well as use patterns, with the advantage of gathering such information quickly within the time limitation of a student practicum and without requiring a great deal of technical expertise. The findings show that although there are some departments with a lower number of monographs in their discipline when considering their size, most fields are well represented by the monograph holdings. It also confirmed that the number of physical sciences and engineering ebooks have overtaken print books and that the physical sciences and engineering print collections are well used relative to McGill's collection as a whole.

All of this data, when combined together with academic department statistics, provides a more complete picture to aid liaison librarians with collections decisions. Print and electronic monograph collections and circulation statistics were compared to department size as determined by number of students and faculty members. Liaison librarians are then able to work from the data both individually and collaboratively to 


\section{Using WCE to analyze monograph holdings by discipline}

make informed decisions on the purchase of print and electronic monographs. The work here is limited to monographs and librarians must also take into account each department's reliance on other types of scientific and technical publications.

Using WCE is a useful first step for determining the composition of a library's collection. It allows librarians to establish what is in the collection and provides a means for breaking it down into manageable chunks for further, deeper analysis. Future research could include analyzing ebook usage statistics as compared with print usage on a subjectby-subject basis, as this is an essential component of collection management that must not be overlooked. Although COUNTER statistics are available from many ebook providers, they were not available within WCE and were beyond the scope of the current study. Developing a method for entering COUNTER statistics into WCE would be of significant value for any library attempting to use the tool for analyzing usage of their collections.

The methods developed here could be of use to librarians in examining how well their collections are serving their user populations and what specific areas could be improved. WCE was used to compare monograph holdings in the physical sciences and engineering to one another and could likewise be used to analyze other subject areas, such as the life sciences or humanities.

\section{REFERENCES}

Benedetto Beals, Jennifer, and Ron Gilmour. 2007. "Assessing Collections Using Brief Tests and Worldcat Collection Analysis." Collection Building 26(4): 104-7. doi: $10.1108 / 01604950710831898$. 


\section{Using WCE to analyze monograph holdings by discipline}

Burke, Merilyn. 2010. "Collection Development and Sustainability at the University of Florida." Against the Grain 22(6):18 \& 20.

Ciszek, Matthew, and Courtney Young. 2010. "Diversity Collection Assessment in Large Academic Libraries." Collection Building 29(4):154-61. doi: 10.1108/01604951011088899.

Culbertson, Michael, and Michelle Wilde. 2009. "Collection Analysis to Enhance Funding for Research Materials." Collection Building 28(1): 9-17. doi:

$10.1108 / 01604950910928466$.

Davis, Hilary, Annette Day, and Darby Orcutt. 2008. "Further Reflections on the WorldCat Collection Analysis Tool." Collection Management 33(3): 236-45. doi: 10.1080/01462670802045566.

Dzurak, Ewa, Kerry A. Falloon, and Jonathan Cope. 2015. "Evaluating and Planning for Interdisciplinary Collection Development: A Case of an East Asian Collection at the College of Staten Island Library." Collection Building 34(2): 51-8. doi: 10.1108/CB01-2015-0002.

Ferguson, Cris. 2015. "A Case for the Use of Collection Analysis Tools in Deselection." Against the Grain 27(2): 16-8.

Genoni, Paul. 2013. "A Distributed National Stored Collection: Testing the Possibilities." Australian Academic \& Research Libraries 44(2): 75-89. doi: 10.1080/00048623.2013.795474.

Genoni, Paul, and Janette Wright. 2010. "Assessing the Collective Wealth of Australian Research Libraries: Measuring Overlap Using WorldCat Collection Analysis." Australian Library Journal 59(4): 197-207. doi: 10.1080/00049670.2010.10736025. 


\section{Using WCE to analyze monograph holdings by discipline}

Henry, Elizabeth, Rachel Longstaff, and Doris Van Kampen. 2008. "Collection Analysis

Outcomes in an Academic Library." Collection Building 27(3): 113-7. doi:

10.1108/01604950810886022.

Hubbard, David E., and Bruce D. Neville. 2012. "Benchmarking Mechanical Engineering Collections Using the Worldcat Collection Analysis Tool." Library Collections, Acquisition and Technical Services 36 (3-4): 59-68. doi:

10.1080/14649055.2012.10766330.

Kelly, Madeline. 2014. "Applying the Tiers of Assessment: A Holistic and Systematic Approach to Assessing Library Collections." The Journal of Academic Librarianship 40(6): 585-91. doi: 10.1016/j.acalib.2014.10.002.

Kohn, Karen. 2013. “Usage-Based Collection Evaluation with a Curricular Focus.” College \& Research Libraries 74(1): 85-97. doi: 10.5860/crl-295.

Machovec, George. 2014. "Shared Print Archiving - Analysis Tools." Journal of Library Administration 54 (1): 66-76. doi: 10.1080/01930826.2014.893118.

McClure, Jennifer Z. 2009. "Collection Assessment through WorldCat." Collection Management 34(2): 79-93. doi: 10.1080/01462670902722213.

McGill Enrolment Services. 2015. “Fall 2014.” www.mcgill.ca/es/registrationstatistics/registration-statistics .

Monroe-Gulick, Amalia, and Lea Currie. 2011. "Using the WorldCat Collection Analysis Tool: Experiences from the University of Kansas Libraries." Collection Management 36(4): 203-16. doi: 10.1080/01462679.2011.604907.

Orcutt, Darby, and Tracy Powell. 2006. "Reflections on the OCLC WorldCat Collection Analysis Tool: We Still Need the Next Step." Against the Grain 18(5): 44. 


\section{Using WCE to analyze monograph holdings by discipline}

Pettijohn, Patricia, Allison Etzel, and Anne Killenberg. 2013. "Graphic Design Collections: Development and Assessment within an Emerging Interdisciplinary Field." In Library Collection Development for Professional Programs: Trends and Best Practices, edited by Sara Holder. Hershey, PA: Information Science Reference.

Spires, Todd. 2006. "Using OCLC's WorldCat Collection Analysis to Evaluate Peer Institutions." Illinois Libraries 86(2):11-9.

Ward, Suzanne M., and Mary C. Aagard. 2008. "The Dark Side of Collection Management: Deselecting Serials from a Research Library's Storage Facility Using WorldCat Collection Analysis." Collection Management 33(4): 272-87. doi: 10.1080/01462670802368638.

White, Howard D. 1995. Brief Tests of Collection Strength: A Methodology for All Types of Libraries. Westport, CT: Greenwood Press. 